\title{
Protozoal and epitheliocystis-like infections in the introduced bluestripe snapper Lutjanus kasmira in Hawaii
}

\author{
Thierry M. Work ${ }^{1, *}$, Robert A. Rameyer ${ }^{1}$, Geraldine Takata ${ }^{2}$, Michael L. Kent ${ }^{3}$ \\ ${ }^{1}$ US Geological Survey, National Wildlife Health Center, Hawaii Field Station, 300 Ala Moana Blvd., Room 5-231, Honolulu, \\ Hawaii 96850, USA \\ ${ }^{2}$ Tripler Army Medical Center, Department of Pathology, 1 Jarrett White Road Honolulu, Hawaii 96859-5000, USA \\ ${ }^{3}$ Center for Fish Disease Research, Oregon State University, Department of Microbiology, 220 Nash, Corvallis, \\ Oregon 97331-3804, USA
}

\begin{abstract}
The bluestripe snapper, or taape, was introduced into Hawaii in the 1950s and has since become very abundant throughout the archipelago. As part of a health survey of reef fish in Hawaii, we necropsied 120 taape collected from various coastal areas south of Oahu and examined fish histology for extraintestinal organisms. Forty-seven percent of taape were infected with an apicomplexan protozoan compatible with a coccidian. Infection was evident mainly in the spleen and, less commonly, the kidney. Prevalence of this coccidian increased with size of fish, and we saw no significant pathology associated with the organism. Twenty-six percent of taape were also infected with an epitheliocystis-like organism that occurred mainly in the kidney and, less commonly, the spleen. In contrast to the coccidian, fish mounted a notable inflammatory response to the epitheliocystis-like organism, and this inflammation appeared to increase in severity with age. Prevalence of the epitheliocystis-like organism infection increased with age, but infection was not seen in fish greater than $26.5 \mathrm{~cm}$ fork length. The high prevalence of coccidial infection in introduced taape prompts the concern that these organisms, along with the epitheliocystis-like organism, have the potential to be transmitted to native reef fish. Given the impact of other introduced microbial organisms on native Hawaiian fauna, there is a clear need to assess whether protozoa and bacteria are endemic to Hawaii, and whether they negatively impact native reef fish that closely associate with taape.
\end{abstract}

KEY WORDS: Bluestripe snapper $\cdot$ Lutjanus kasmira $\cdot$ Apicomplexa $\cdot$ Protozoa $\cdot$ Epitheliocystis-like organism · Pathology · Epizootiology

Resale or republication not permitted without written consent of the publisher

\section{INTRODUCTION}

The bluestripe snapper Lutjanus kasmira, or taape, was introduced into Hawaii in 1958 with the release of ca. 2400 fish into Kaneohe Bay, Oahu, from the Marquesas (Randall 1987). Since then, the taape has successfully established itself in large numbers on all the Hawaiian Islands, including the remote northwestern islands (Oda \& Parrish 1981). Fishermen in Hawaii dislike the taape because of its aggressive competition for bait, and believe this fish is responsible for the displacement of more desirable native game fish (Randall
1987). Although no direct competition between native fish and taape has been documented, taape do share the same habitat and closely associate with certain native fish such as goatfish Mulloidichthys sp. (Friedlander et al. 2002). Presumably, taape could compete with native fish through habitat use, diet, predation on larvae, or disease transmission to native fish.

Knowledge of disease and parasite infections in Hawaiian reef fish is very limited. Yamaguti (1968, 1970) and Rigby \& Font (1997) have documented several intestinal metazoans in native reef and riverine fish in Hawaii, and Font \& Rigby (2000) suspected 
that at least one nematode species was introduced into Hawaii with the importation of taape. Okihiro (1988) found a high prevalence of skin tumors on native butterfly fish (Chaetodon multicinctus and C. miliaris) in Maui, and suspected contaminants as a possible cause, based on the distribution of affected fish. Kent \& Heidel (2001) found that pen-raised opakaka Pristipomoides filamentosus suffered mainly from bacterial infections of swim bladder and hemorrhage and emphysema of the eyes, although various protozoan and metazoan parasites were noted at low infection levels.

As part of a larger study, taape caught near Oahu were surveyed for systemic parasites to provide baseline information on their health status.

\section{MATERIALS AND METHODS}

During 2001 and 2002, fish were collected using the line and hook method at depths ranging from 15 to $70 \mathrm{~m}$ throughout Southern Oahu. Fish were anesthetized with MS-222 in seawater, and bled from the caudal tail vein using sterile $3 \mathrm{cc}$ syringes and $1 \times 38 \mathrm{~mm}$ needles. Blood smears were made immediately, air dried, and fixed in absolute methanol. Fish were then humanely euthanized with an overdose of MS-222 in seawater. Necropsies consisted of measuring total and fork length $(0.5 \mathrm{~cm})$ with a ruler, weight $(0.1 \mathrm{~g})$ with an electric scale, and a complete external and internal exam. Spleen, liver, cranial and caudal kidneys, swim bladder, brain, heart, skeletal muscle, gill, and gonad were stored in $10 \%$ neutral buffered formalin. Tissues were processed for histology by paraffin embedding, sectioning at $5 \mu \mathrm{m}$, and staining with hematoxylin and eosin. Tissues were examined microscopically for presence of lesions and signs of infectious organisms. Giemsa was used to identify protista, and Gimenez, and Gram stains were used to identify bacteria (Prophet et al. 1992). Protista included microsporidians and coccidia, bacteria included epitheliocystis-like organisms, and metazoans included myxozoa, trematodes or their eggs, and migratory tracts associated with helminth. For electron microscopy, tissues were fixed in Trump's fixative (McDowel \& Trump 1976), rinsed in $0.1 \mathrm{M}$ Sorenson's phosphate buffer, and post fixed in $2 \%$ osmium tetroxide. Epoxy embedded tissues were cut into $1 \mu \mathrm{m}$ thick toluidine blue-stained sections. Ultrathin sections were stained with uranyl acetate, post stained with lead citrate and examined with a Zeiss EM 109 electron microscope. Blood smears were stained with Wright's Giemsa and examined for the presence of hemoparasites.

Data were tested for normality and equal variance. We used linear regression to evaluate the relationship between weight and fork length, the $t$-test to evaluate the difference in weight between males and females, and ANOVA to compare weights of parasitized and parasite-free fish (Daniel 1987). For all comparisons, $\alpha=0.05$.

\section{RESULTS}

A total of 120 taape (78 males, 42 females) were examined. Mean weight (mean \pm SD) of males $241.7 \pm$ 59.5 was significantly $(t=6.2, \mathrm{df}=118, \mathrm{p}<0.001)$ greater than that of females $178.7 \pm 40.2$. Grossly, no lesions were seen other than trauma associated with capture. There was a significant relationship between fork length and weight $\left(F=1535, \mathrm{df}=119, \mathrm{R}^{2}=0.93\right.$, $\mathrm{p}<0.0001$ ).

With microscopy, protista were the most common organisms, which infected $56(47 \%)$ fish. Of these, infection was in the spleen (42 fish), kidney (4 fish), or both organs (10 fish). Protista were in well-defined multicellular aggregates (Fig. 1A,B), and were sometimes heavily infiltrated with melanized macrophages. Some appeared banana shaped with an eosinophilic cytoplasm, while others appeared to have multiple nuclei. They stained weakly positive with Giemsa and were not associated with tissue necrosis. On electron microscopy, protista were intracytoplasmic within monocytes and appeared to displace the host nucleus (Fig. 1C). The organisms were sausage-shaped, and sometimes were grouped within a membrane. Individual organisms had a distinct nucleus, conoid, rhoptries, amylopectin granules and micronemes (Fig. 1D). No hemoparasites were seen on smears of peripheral blood.

Bacteria compatible in morphology with the epitheliocystis-like organism were seen in 26 (22\%) fish. Of these, infection was in the kidney (23 fish), spleen (2 fish), or both organs (1 fish). On light microscopy, the epitheliocystis-like organism consisted of well-defined spherical aggregates of basophilic organisms that stained negative with Gram stain and positive with Gimenez and Giemsa. In putative early infections, organisms were amorphous and homogenous and were accompanied by a mild mononuclear response or no inflammation (Fig. 2A). In later infections, particularly in the kidney, epitheliocystis-like organisms became infiltrated with clumps of eosinophilic material and were surrounded by a prominent capsule of collagen mixed with fibroblasts (Fig. 2B). On electron microscopy, epitheliocystis-like organisms had a thick capsule (Fig. 2C) surrounding a granular matrix containing mitochondria in various stages of degeneration (Fig. 2D). Deeper into the organism, a thin inner membrane (Fig. 2E) surrounded variably sized aggregates of membrane-bound spherical structures, ranging in diameter from 1 to $2 \mu \mathrm{m}$. These structures contained 

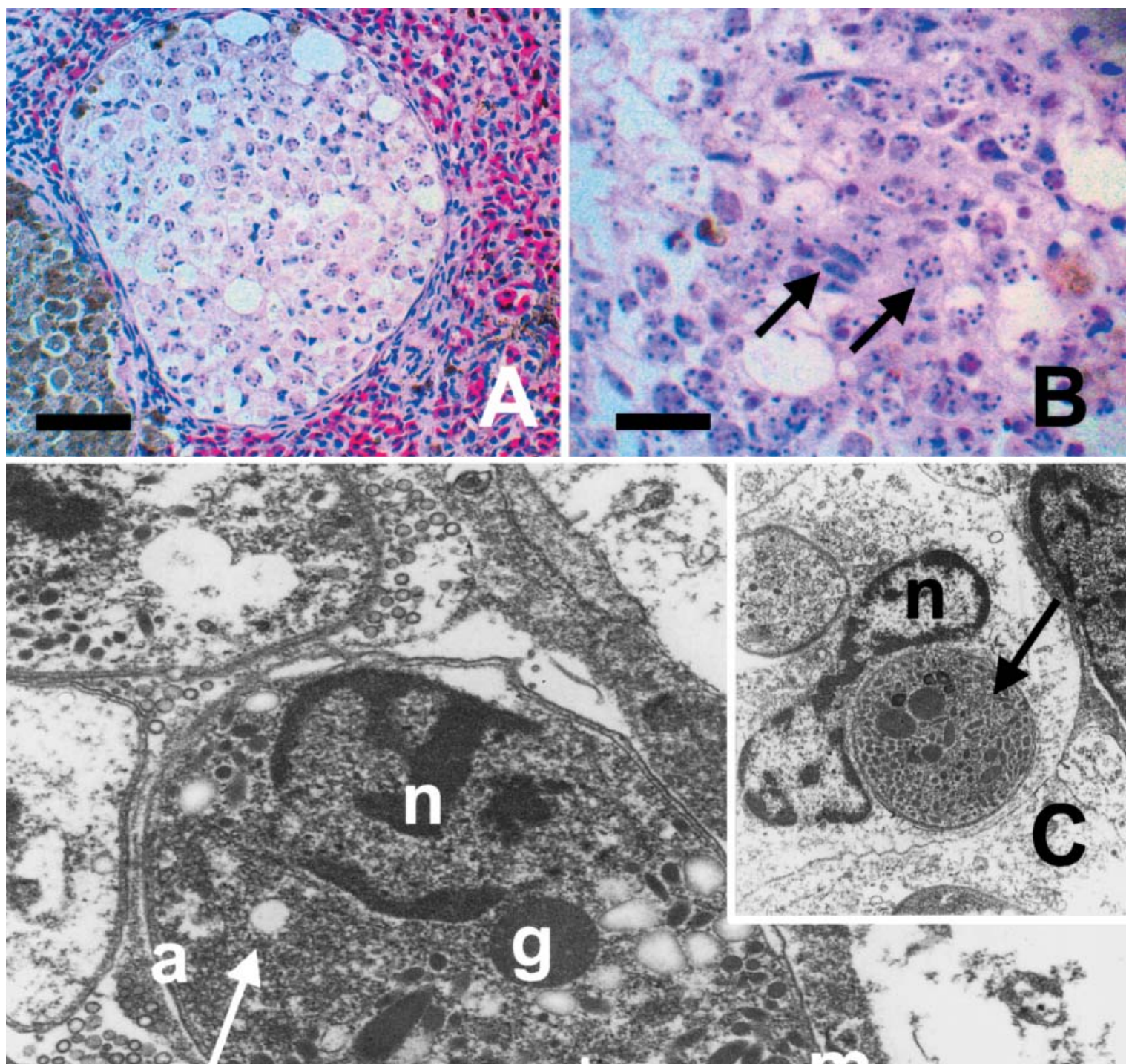

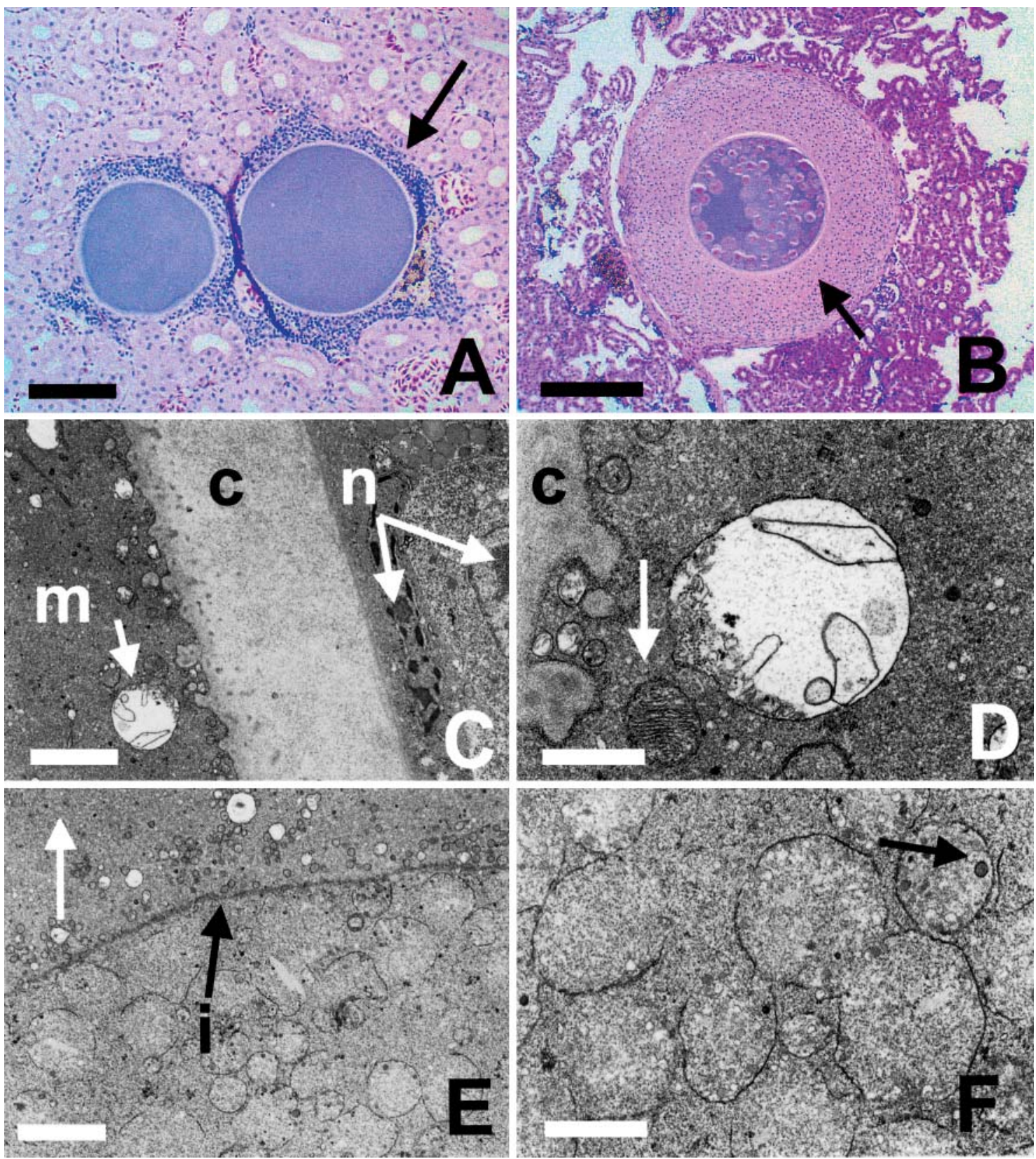

Fig. 2. Lutjanus kasmira. (A) Epitheliocystis-like organism in kidney. Note mild mononuclear response (arrow). Scale bar $=100 \mu$ m. (B) Epitheliocystis-like organism in kidney putative late infection. Note prominent connective tissue capsule (arrow) surrounding organism mixed with clumps of eosinophilic material. Scale bar $=200 \mu \mathrm{m}$. (C) Transmission electron micrograph of epitheliocystislike organism. Note compressed host cell nuclei (n), and capsule (c) surrounding granular matrix with vacuolated mitochondria (m). Scale bar $=2 \mu \mathrm{m}$. (D) Close-up of $(\mathrm{C})$. Note intact mitochondria (arrow). Scale bar $=1 \mu \mathrm{m}$. (E) Inner membrane (i, black arrow) enclosing aggregates of spherical structures. White arrow points to capsule seen in (C). Scale bar $=2 \mu \mathrm{m}$. (F) Close-up of spherical structures in (E). Note lack of membrane-bound organelles and occasional electron-dense granules (arrow). Scale bar $=1 \mu \mathrm{m}$

aggregates of crystalloid and occasional electron-dense granules, but no recognizable nuclei or other membrane-bound organelles (Fig. 2F).

Remaining infections were considered incidental. One fish had an infection with putative myxosporea associated with necrosis in the brain (Fig. 3A,B).
These were exemplified by aggregates of fusiform binucleated organisms that stained strongly positive with Giemsa and that were surrounded by encapsulated necrotic debris. Organisms compatible with microsporidia were seen in the liver, kidney, and skeletal muscle of 1 fish each (Fig. 3C,D). In the liver, 

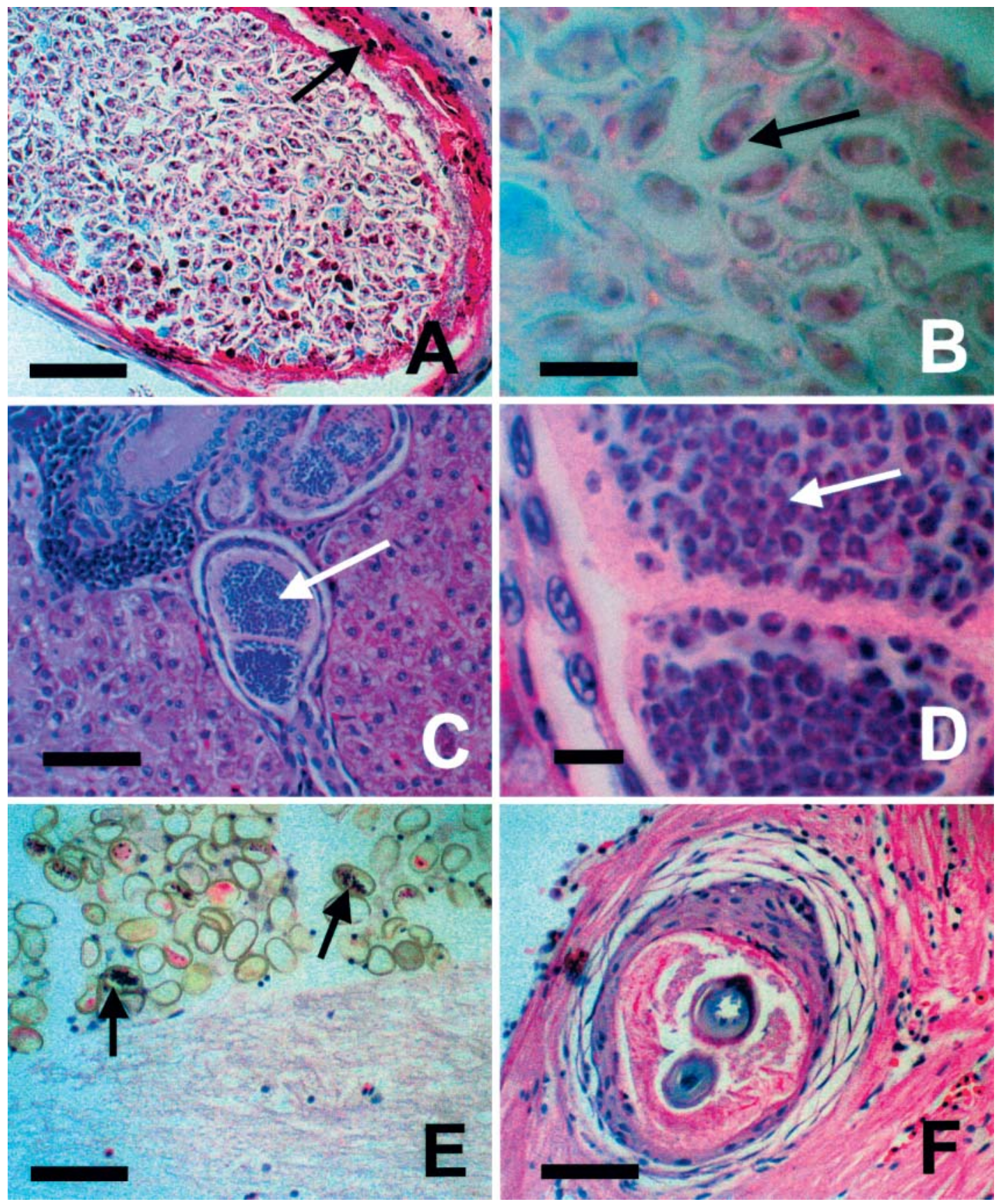

Fig. 3. Lutjanus kasmira. (A) Myxosporean in brain. Note capsule surrounding organisms (arrow). Scale bar $=50 \mu \mathrm{m}$. (B) Close-up of myxosporeans in (A) (arrow). Scale bar $=10 \mu \mathrm{m}$. (C) Microsporidian in liver in bile ducts. Scale bar $=50 \mu \mathrm{m}$. (D) Close-up of (C) (arrow). Scale bar $=10 \mu \mathrm{m}$. (E) Trematode eggs in brain. Note embryonated eggs (arrows). Scale bar $=50 \mu \mathrm{m}$. (F) Encapsulated metacercaria in heart. Scale bar $=50 \mu \mathrm{m}$

these were characterized by aggregates of small basophilic coccoid organisms within biliary ducts, with little to no associated inflammation. Trematode eggs with no associated inflammation were seen in the brain of 3 fish (Fig. 3E), and encapsulated trematode eggs were noted in the spleen in 1 fish. Trema- tode cercaria or putative migratory tracts of parasites were seen in liver, heart and kidney of 5, 2, and 1 fish, respectively (Fig. 3F).

Weight $( \pm$ SD) of fish infected with protozoa $(238.0 \pm$ $63)$ or epitheliocystis-like organisms $(236.0 \pm 59.2)$ was significantly greater $(F=7.2, \mathrm{df}=132, \mathrm{p}<0.001)$ than 


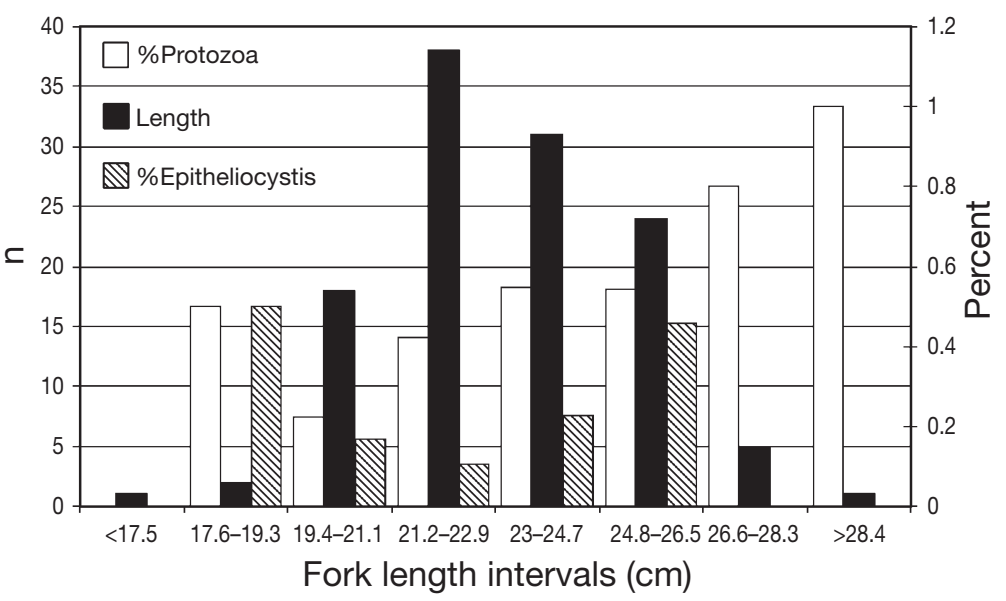

Fig. 4. Lutjanus kasmira. Frequency distribution of fork lengths of taape, and percent with protozoal and epitheliocystis-like organism infection in each length interval

that of parasite-free fish $(197.8 \pm 52.6)$. Prevalence of infection with protozoa and protista was relatively high in small fish, then dropped and progressively increased as fish increased in size, except for epitheliocystis-like organisms where prevalence dropped off in animals greater than $26.5 \mathrm{~cm}$ (Fig. 4). There was no sex or geographic pattern for parasitized versus parasite-free fish (data not shown).

\section{DISCUSSION}

The protozoa in the spleen and kidney of taape were compatible in morphology with apicomplexa based on presence of rhoptries, conoids, amylopectin granules, and micronemes (Levine 1985). Based on lack of evident blood stages, we suspect that taape were infected with extraintestinal coccidia. Intestinal coccidia are common in marine and freshwater fish; however, extraintestinal coccidia are less common (Lom \& Dykova 1992, Molnár 1995). Although numerous extraintestinal coccidia have been reported in fishes, these usually contain various developmental stages, including gamonts and oocysts. With light and electron microscopy, the organisms from taape most resembled coccidia in hardy head fish Atherinomorus capricornensis, where infection was characterized by massive infection of asexual stages in the pancreas and mesenteries, and sexual stages were not observed (Kent et al. 1989). The organism also bore resemblance to coccidian cysts found in musculature of Liza subviridis (Paperna \& Sabnai 1982) and head kidney of Sparus aurata (Paperna 1979). Further ultrastructural, molecular, and life-cycle studies would be needed to best classify the genus and species of the coccidia reported here.
Although there was no severe tissue necrosis associated with coccidial infection in taape, the prevalence of infection (47\%) appeared high. Prevalence of extraintestinal coccidia in other wild fish can be low (<10\%) (Morrison \& Poynton 1989a, Oliveira et al. 1993). However, a prevalence of $16 \%$ has been seen in cod (Morrison \& Poynton 1989b), and liver infections with Calyptospora fundli have reached epizootic proportions in gulf killifish (Duszynski et al. 1979), with prevalence reaching $100 \%$ and with large numbers of organisms in the liver of affected fish. Fewer studies examine the prevalence of extraintestinal coccidial infections in relation to size (age) of fish. Morrison \& Poynton (1989a) found that prevalence of Goussia in cod decreased with increasing size of fish. Conversely, Morrison \& Hawkins (1984) found that the prevalence of coccidians in herrings increased with size.

Mortality caused by parasite infections in wild fish populations is often difficult to confirm (Sinderman 1990, Kent \& Fournie 1993). Two of the most striking examples of this is whirling disease in wild rainbow trout Oncorhynchus mykiss (Hedrick et al. 1998) and Ichthyophonus in Atlantic herring Clupea harengus (Patterson 1996). Examples of parasite-induced mortalities in other marine animals include Caryospora cheloniae in green sea turtles (Gordon et al. 1993). There are many examples of disease caused by apicomplexans in cultured fishes, but only a few in wild fish (Molnár 1995). Fournie (1985) concluded that Calyptospora fundli caused mortality in the wild killifish when water temperatures declined, and Odense \& Logan (1976) reported that Goussia gadi caused mortality in haddock. Chronic infections in which the host remains infected for its life time are suitable for investigations, as simple models can be developed using age/prevalence data in which convex curves of mean parasite abundance with respect to age provide evidence of pathogen-induced mortality (Anderson \& Gordon 1982, Lester 1984). The dip in prevalence of apicomplexan infection in mid-size taape (19.5 to $21 \mathrm{~cm}$ ) suggests early mortality; however, with age, fish appear to survive infection based on increased prevalence with age.

Given that the Hawaiian Islands are depauperate in fauna and flora because of their geographic isolation, we propose three explanations for the high prevalence of coccidia in taape: (1) Taape are more susceptible to infection with coccidia because they are somehow predisposed to infection due to factors like immune suppression; (2) taape are subjected to heavy and repeated exposure to coccidia that were introduced with them from the Marquesas; or (3) taape are naïve hosts being infected with a native Hawaiian coccidia. 
The high prevalence of protozoans in taape is of concern because taape associate closely with native Hawaiian goatfish and opakapaka. We suspect the high prevalence of protozoa in taape could be, in part, due to their bottom-feeding habits, thus providing ample opportunity to ingest intermediate hosts. Future studies should concentrate on assessing the risk of extraintestinal coccidial infection in native fish that are associated closely with taape and determining whether these organisms infect taape in their native range in the Marquesas.

In contrast to classical epitheliocystis infections that occur in the gills, our finding of epitheliocystis-like structures in kidney and spleen was unusual. Although the light microscopic appearance and staining characteristics (Gram negative and positive with Gimenez stains) were similar to epitheliocystis found in the gills of various fish (Crespo et al. 1999), the ultrastructural appearance differed. Epitheliocystis are intracellular round organisms, usually less than $1 \mu \mathrm{m}$ in diameter, with an electron-dense nucleopasm surrounded by an electrolucent halo and electron-dense ribosomes, and aggregates of epitheliocystis are surrounded by a thin capsule (Paperna \& Alves de Matos 1984, Crespo et al. 1999). In contrast, the structures in taape had a thick capsule surrounding a granular matrix containing degenerating mitochondria. This matrix in turn surrounded a thin inner membrane that contained numerous spherical membrane-bound structures, ranging in size from 1 to $3 \mu \mathrm{m}$ in diameter with no evident nuclear structure. Lack of nuclei or other membranebound organelles lead us to suspect we are seeing a prokaryote, hence our nomenclature of epitheliocystislike. Taape with this organism formed a mononuclear inflammatory response that appeared to progress to chronicity with formation of a capsule of fibroblast cells, and this inflammation appeared more severe with age (data not shown). Similar capsules were occasionally noted in pen-raised opakapaka in Hawaii (Kent \& Heidel 2001), suggesting that other native fish may also be affected by this organism. Based on inflammatory response, and drop in prevalence in larger fish, we suspect these epitheliocystis-like organisms may cause morbidity and mortality in taape. Prevalence of infection with this organism was much lower than for protozoa, again suggesting that survival of fish infected with this organism may be low, or that opportunities for infection are more limited. Future studies will need to elucidate the identity of this structure, perhaps by examining early- and late-stage infections.

One taape had cerebral organisms compatible in morphology with myxosporeosis. Myxosporea of taape were most similar in morphology to Henneguva (Lom 1984) based on the fusiform shape and bifurcate caudal extensions. Definitive identification of these or- ganisms would require observations of spores in wetmount preparations. Cerebral (Hedrick et al. 1998) and muscle (Moran \& Kent 1999) myxoporea cause severe diseases in anadromous fish; however, given the low prevalence of cerebral myxosporea in taape, we suspect this parasite does not play a significant role in diseases of taape.

Microsporidians were rarely seen and were not associated with significant pathology, although microsporodians are capable of infecting a variety of organs, causing massive nodules (xenomas) in marine fish (Lom 1984, Shaw \& Kent 1999). The presence of a variety of trematodes was expected. Marine fish in Hawaii are infected with many different nematodes and trematodes (Yamaguti 1968, 1970, Rigby \& Font 1997), and based on low prevalence and minimal pathology, we suspect these trematodes do not play a significant role in the health of taape in Hawaii.

Acknowledgements. The authors thank Alvin Muranaka, Gary Voitovich and the city and county of Honolulu for collecting fish. This work was funded in part by the Water Resources Division of the University of Hawaii. Thanks to F. Murado, J. Winton and anonymous reviewers for constructive comments.

\section{LITERATURE CITED}

Anderson RM, Gordon DM (1982) Processes influencing the distribution of parasite numbers within host populations with special emphasis on parasite-induced host mortalities. Parasitology 85:373-398

Crespo S, Zarza C, Padros F, Marin de Mateo M (1999) Epitheliocystis agents in sea bream Sparus aurata: morphological evidence for two distinct chlamydia-like developmental cycles. Dis Aquat Org 37:61-72

Daniel WW (1987) Biostatistics: a foundation for analysis in the health sciences. John Wiley and Sons, New York, NY

Duszynski DW, Solangi MA, Overstreet RM (1979) A new and unusual eimerian (Protozoa: Eimeriidae) from the liver of the gulf killifish, Fundulus grandis. J Wildl Dis 15:543-552

Font WF, Rigby MC (2000) Implications of a new Hawaiian host record from blue-lined snappers Lutjanus kasmira: is the nematode Spirocamallanus istiblenni native or introduced? Bishop Mus Occ Pap 64:53-55

Fournie JW (1985) The biology of Calyptospora funduli from atheriniform fishes. PhD thesis. University of Mississippi, Oxford, MS

Friedlander AM, Parrish JD, DeFelice RC (2002) Ecology of the introduced snapper Lutjanus kasmira (Forsskal) in the reef fish assemblage of a Hawaiian Bay. J Fish Biol 60:28-48

Gordon AN, Kelly WR, Lester RJ (1993) Epizootic mortality of free-living green turtles, Chelonia mydas, due to coccidiosis. J Wildl Dis 29:490-494

Hedrick RP, El-Matbouli M, Adkison MA, MacConnell E (1998) Whirling disease: re-emergence among wild trout. Immunol Rev 166:365-376

Kent ML, Fournie JW (1993) Importance of marine fish diseases-an overview. In: Fournie JW, Couch JA (eds) The pathobiology of marine and estuarine organisms. CRC Press, Boca Raton, FL, p 1-24 
Kent ML, Heidel J (2001) Diseases of opakapaka held at the Hawaii Institute of Marine Biology. Report Hawaii Institute of Marine Biology, Honolulu, HI

Kent ML, Moser M, Fournie JW (1989) Coccidian parasites (Apicomplexa: Eucoccidorida) in hardy head fish, Atherinomorus capricornensis (Woodland). J Fish Dis 12:179-183

Levine N (1985) Veterinary protozoology. Iowa State University Press, Ames, IA

Lester RJG (1984) A review of methods for estimating mortality due to parasites in wild fish populations. Helgol Meeresunters 37:53-64

Lom J (1984) Diseases caused by protistans. In: Kinne O (ed) Diseases of marine animals, Vol IV. Biologische Anstalt Helgoland, Hamburg, p 114-168

Lom J, Dykova I (1992) Protozoan parasites of fishes. Development in Aquaculture and Fisheries Science, 26. Elsevier, Amsterdam

McDowell E, Trump B (1976) Histological fixatives for diagnostic light and electron microscopy. Arch Pathol Lab Med 100:405-414

Molnár K (1995) Phylum Apicomplexa. In: Woo PTK (ed) Fish diseases and disorders, Vol 1. Protozoan and metazoan infections. CABI Publishing, Wallingford, p 263-288

Moran JDW, Kent ML (1999) Kudoa thyrsites (Myxozoa: Myxosporea) infections in pen-reared Atlantic salmon in the Northeast Pacific Ocean with a survey of potential non-salmonid reservoir hosts. J Aquat Anim Health 11: 101-109

Morrison CM, Hawkins WE (1984) Coccidians in the liver and testis of the herring Clupea harengus L. Can J Zool 62:480-493

Morrison CM, Poynton L (1989a) A new species of Goussia (Apicomplexa, Coccidia) in the kidney tubules of the cod, Gadus morhua L. J Fish Dis 12:533-560

Morrison CM, Poynton L (1989b) A coccidian in the kidney of the haddock, Melanogrammus aeglefinus (L.). J Fish Dis 12:591-593

Oda DK, Parrish JD (1981) Ecology of commercial snappers and groupers introduced to Hawaiian reefs. Proc 4th Int Coral Reef Symp 1:59-67

Editorial responsibility: Wolfgang Körting, Hannover, Germany
Odense PH, Logan VH (1976) Prevalence and morphology of Eimeria gadi in haddock. J Protozool 23:564-571

Okihiro MS (1988) Chromatophoromas in two species of Hawaiian butterflyfish, Chaetodon multicinctus and $C$. miliaris. Vet Pathol 25:422-431

Oliveira MFT, Hawkins WE, Overstreet RM, Fournie JW (1993) Calyptospora funduli (Apicomplexa, Calyptosporidae) in the liver of the gulf toadfish, Opsanus beta. J Helminth Soc Washington 60:273-277

Paperna I (1979) Sporozoan infection in cultured Sparus aurata L. and wild Siganus luridus. Ann Parasitol Hum Comp 54:385-392

Paperna I, Alves de Matos AP (1984) The developmental cycle of Epitheliocystis in carp, Cyprinus carpio L. J Fish Dis 7:137-147

Paperna I, Sabnai I (1982) A coccidian cyst stage in musculature of Liza subviridis (Mugilidae). Z Parasitenkd 68: $161-170$

Patterson KR (1996) Modeling the impact of disease-induced mortality in an exploited population: the outbreak of the fungal parasite Ichthyophonus hoferi in the North Sea herring (Clupea harengus). Can J Fish Aquat Sci 53:2870-2887

Prophet EB, Mills B, Arrington JB, Sobin LH (1992) Laboratory methods in histotechnology. Armed Forces Institute of Pathology, Washington, DC

Randall JE (1987) Introduction of marine fishes to the Hawaiian Islands. Bull Mar Sci 41:490-502

Rigby MC, Font WF (1997) Redescription and range extension of Spirocamallanus istiblenni Noble, 1966 (Nematoda: Camallanidae) from coral reef fishes in the Pacific. J Helminthol Soc Wash 64:227-233

Shaw RW, Kent ML (1999) Fish Microsporidia. In: Wittner M (ed) Microsporidia and Microsporidiosis. ASM Press, Washington, DC, p 418-446

Sinderman CJ (1990) Principal diseases of marine fish and shellfish. Academic Press, New York, NY

Yamaguti S (1968) Monogenetic trematodes of Hawaiian fishes. University of Hawaii Press, Honolulu, HI

Yamaguti S (1970) Digenetic trematodes of Hawaiian fishes. Keigaku Publishing, Tokyo

Submitted: March 5, 2003; Accepted: May 26, 2003

Proofs received from author(s): September 15, 2003 